\title{
УЧЕБНАЯ ДЕЛОВАЯ ИГРА "ИНТЕЛЛЕКТУАЛЬНЫЙ ХОККЕЙ" КАК ЭФФЕКТИВНЫЙ ИНСТРУМЕНТ ФОРМИРОВАНИЯ ПРОФЕССИОНАЛЬНО-ОРИЕНТИРОВАННОЙ КОММУНИКАТИВНОЙ КОМПЕТЕНЦИИ ПРИ ОБУЧЕНИИ ИНОСТРАННОМУ ЯЗЫКУ БУДУЩИХ СПЕЦИАЛИСТОВ В СФЕРЕ ТУРИЗМА
}

\section{EDUCATIONAL BUSINESS GAME "INTELLECTUAL HOCKEY" AS AN EFFECTIVE TOOL FOR BUILDING PROFESSIONALLY-ORIENTED COMMUNICATIVE COMPETENCE IN TEACHING FOREIGN LANGUAGES TO FUTURE SPECIALISTS IN THE FIELD OF TOURISM}

\section{A. Volkova \\ A. Glagolev \\ S. Korshunova}

Summary: The article deals with the process of developing professional skills of students studying "Tourism" with sub-speciality "Guiding" at MSIPCST n.a. Yu.A. Senkevich, Moscow, by means of introducing gaming technologies into the pedagogical process. The analysis of a number of psychological and pedagogical works on the problem is presented. Using the example of "Intellectual Hockey" game, the authors prove the importance and usefulness of introducing gaming technologies in the process of teaching students a professionally oriented foreign language. The article describes an experimental game "Intellectual Hockey" aimed at developing the basic skills and abilities of future specialists in the field of tourism and hospitality.

Keywords: professionally-oriented foreign language, intercultural professionally oriented competence, motivation, communication needs, gaming technologies, tourism and hospitality industry, foreign language.

Волкова Анна Юрьевна

Старший преподаватель, Московский Государственный институт физической культуры, спорта и туризма имени Ю.А. Сенкевича

sallyvolkova@gmail.com

Глаголев Александр Борисович

Старший преподаватель, Московский Государственный институт физической культуры, спорта и туризма имени Ю.А. Сенкевича

glagol3@yandex.ru

Коршунова Светлана Ивановна

Старший преподаватель, Московский Государственный институт физической культуры, спорта и туризма имени Ю.А. Сенкевича ksi_0101@mail.ru

Аннотация: В статье рассматривается процесс развития профессиональных навыков студентов, обучающихся по профилю "Экскурсионная деятельность" в МГИФКСиТ им. Ю.А. Сенкевича г. Москва, при помощи активного внедрения в педагогический процесс игровых технологий. В статье представлен анализ ряда педагогических и психологических работ по данной проблеме. На примере проведения игры "Интеллектуальный хоккей" авторы доказывают безусловную важность и полезность введения игровых технологий в процесс обучения студентов профессионально-ориентированному иностранному языку. В статье приводится описание экспериментальной деловой игры "Интеллектуальный хоккей", направленной на формирование основных навыков и умений будущих специалистов в области туризма и гостеприимства. Для изучения проблемы был использован метод эмпирического исследования - педагогический эксперимент, а также метод сбора данных - тестирование и анкетирование. Авторами представлен количественный и качественный анализ эмпирических данных, полученных в результате проведения предлагаемой игры, описываются результаты экспериментальной работы, которые показали эффективность проведения подобных игр на занятиях по профессионально-ориентированному иностранному языку.

Ключевые слова: игровые технологии; профессионально-ориентированная компетенция; языковые и коммуникативные навыки; иностранный язык в неязыковом вузе; мотивация.

\section{Введение}

C овременный подход к обучению иностранному языку в неязыковом вузе предполагает конкретизацию параметров компетентностного и личностно-ориентированного учебного процесса с целью

формирования межкультурной профессионально-ориентированной коммуникативной компетенции [10].

Актуальность темы исследования определяется важностью и значительностью того факта, что системное включение в учебный процесс элементов профессио- 
нального дискурса и имитирование ситуаций, специфичных для будущей профессии студентов, во время обучения иностранному языку способствует формированию профессиональной иноязычной компетенции, которая рассматривается как приоритетная конечная прагматическая цель в программах высшего образования [4, 7, 8, 12].

Научная новизна данной работы заключается в том, что впервые для обучения английскому языку будущих специалистов в сфере туризма и гостеприимства применяется учебная деловая игра "Интеллектуальный хоккей", содержащая соответствующий лексический и грамматический материал.

Особые требования предъявляются к владению иностранным языком специалистами, работающим в сфере туризма и гостеприимства, т.к. свободное владение иностранными языками является одним из важнейших элементов профессиональной компетенции такого сотрудника. Плохое владение английским языком, плохая межкультурная коммуникативная компетенция могут привести к трудностям в привлечении и обслуживании туристов.

Обучающие игры появились много лет назад. Но актуальность использования игровых методов в процессе обучения всегда будет приводить к появлению новых игр. Такой игрой является игра "Интеллектуальный хоккей", проводимая в МГИФКСиТ им. Ю.А. Сенкевича с 2017 года. Отличительной чертой предлагаемой игры является ее комплексность, т.е. направленность на одновременное формирование целого ряда навыков и умений, необходимых специалисту индустрии туризма.

Цель исследования - доказать, что использование деловой игры "Интеллектуальный хоккей" повышает эффективность формирования иноязычной профессиональной коммуникативной компетенции студентов в неязыковом вузе.

Поэтапное достижение поставленной цели состоит из выполнения следующих задач:

- изучить имеющиеся научно-педагогические труды, посвященные игровым технологиям;

- опытно-экспериментальным путем проверить результативность проведения деловой игры "Интеллектуальный хоккей" для формирования профессионально-ориентированной коммуникативной компетенции, основными составляющими которой являются соответствующие знания, навыки и умения, мотивация к профессиональному саморазвитию.

Для изучения проблемы был использован метод эмпирического исследования - педагогический эксперимент, который проводился в МГИФКСиТ им. Ю.А. Сен- кевича, а также метод сбора данных - тестирование и анкетирование.

Теоретической базой исследования являются научные труды отечественных лингвистов, посвященные проблемам коммуникативного подхода к обучению иностранным языкам: Е.А Стародубцевой [11], Е.Г. Ляховой $[7,8]$, Н.Ю. Мороз, Е.П. Цацкиной [8] и работы, посвященные применению игровых технологий в обучении иностранным языкам:О.А. Артемьевой [1], А.М. Бершадского, Е.Е. Янко [2], О.Ю. Левченко [6], Ю.И. Мишеневой [9].

Результаты проведенного исследования имеют практическую значимость для совершенствования образовательного процесса в неязыковых вузах, использование данной деловой игры позволит преподавателям с новых позиций подойти к подготовке студентов к иноязычной речевой коммуникации. На основе деловой игры "Интеллектуальный хоккей" могут быть разработаны другие деловые игры на других языках и для других контингентов учащихся.

\section{Теоретический аспект}

Игровые технологии занимают все более значимое место в процессе освоения иностранных языков в неязыковых вузах. Впрочем, данное утверждение справедливо и по отношению к учебным заведениям лингвистической направленности [11]. Широкому развитию игровых технологий в педагогическом процессе способствует целый ряд объективных предпосылок. Поскольку общеизвестным фактом является тесная связь между процессами, происходящими в обществе и в языке, современное развитие общества накладывает существенный отпечаток на формирование и развитие компетенций у студентов.

Развитие России в последние десятилетия характеризуется все большим отходом от "командно-административных" методов управления всеми процессами, в том числе и в области педагогики. Старые модели, когда студент выучивал определенные правила, а затем применял их в упражнениях (часто далеких по своему содержанию от реальной жизни), встречают все большее непонимание и отторжение у обучающихся. Современный студент - это продукт другой эпохи, преподаватели часто встречаются с критически мыслящими творческими личностями, не готовыми работать по старым отжившим лекалам. Да и задачи формирования социально-активного, практико-ориентированного специалиста является на сегодняшний день одной из важнейших задач высшей школы [1]. В этом свете игровые технологии позволяют не снабжать студента набором знаний, а позволяют ему "добывать" эти знания и применять их в практической ситуации, способствуют формированию способности прогнозировать и принимать решения. 
Многие авторы подчеркивают, что в современных условиях студенты все более нацелены на применение полученных знаний на практике в короткие сроки, т.е. говоря об овладении иностранным языком, для них это не набор знаний, а пути реализации целей. Этому способствует и политика большинства вузов, где прохождение практики студентами уже на начальных курсах рассматривается как важнейший фактор их обучения будущей профессии [9].

Часто отмечается, что "ценность" овладения иностранным языком у современного первокурсника не вызывает сомнений, т.е. мы сталкиваемся, как правило, с высокомотивированным студентом. Задача преподавателя показать, что полученные знания и умения будут немедленно применены в реальных ситуациях [13].

Таким образом, участвуя в игровом процессе, студент имеет возможность не только преодолевать речевой барьер, но знает и умеет применять "тот английский язык", который используется непосредственно в той отрасли, где он собирается работать.

Интересно отметить, что роль игровых методов возрастает на всех этапах изучения иностранных языков. Даже традиционно "консервативный" процесс изучения грамматики все более и более склоняется к применению игровых технологий. Так О.Ю. Левченко указывает: "Широко используются и игровые упражнения, приближающие процесс тренировки к реальному общению. Примерами таких игр может быть "Снежный ком", когда составляется коллективный рассказ, при котором каждый повторяет все предшествующие фразы и добавляет свою ... Формирование грамматических навыков может осуществляться и в ходе ролевой игры, например, при изучении темы "Hotel", "At the Supermarket", когда обучающиеся многократно используют определенные грамматические конструкции, изученные ранее" [6].

В последнее время все чаще авторы стали обращать внимание на еще один безусловный плюс применения игровых технологий в процессе обучения иностранному языку. Не секрет, что нагрузки на современного студента постоянно и существенно растут. Налицо явный разрыв между все возрастающими объемами информации и способностями среднего обучающегося воспринимать такие объемы. Применение традиционных подходов ведет к переутомлению и психическому срыву.

"Психосберегающие технологии организации обучения и воспитания студентов высших учебных заведений в ситуации всё нарастающих перегрузок являются необходимой предпосылкой как сохранения психического здоровья обучающихся, так и повышения эффективности образовательного процесса. Проблема разработки технологий психосбережения и выявления психологопедагогических условий их эффективной реализации в современной высшей школе является весьма актуальной" [11].

Одним из важнейших элементов таких технологий выступают игровые методики. Их широкое применение, помимо всего прочего, позволяет разгрузить студента, при этом, не снижая качество учебного процесса.

Отмечая безусловную полезность применения игровых технологий для формирования компетенций у учащихся, отмечаются и определенные риски при неправильном формировании этого процесса. Профессор А.М. Бершадский отмечает в качестве негативных факторов внешнюю мотивацию (как погоню за баллами и наградами), которая в конечном счете подменяет внутреннюю мотивацию (как стремление овладеть новыми знаниями и навыками), психологические проблемы при получении и утере наград, подрывающие поведение и др. Автор отмечает определенные риски при переходе из "игрового" режима решения проблем к реальным жизненным ситуациям, где принятые решения ведут к настоящим последствиям, а не к потере баллов. Снижение ответственности за принятые решения ни в коем случае не должны стать результатом широкого применения игровых технологий [2].

\section{Эксперимент и его результаты}

Критерием эффективности экспериментального обучения служила оценка динамики усвоения учащимися системы знаний и овладение ими умениями и навыками, необходимыми для формирования профессиональноориентированной коммуникативной компетенции.

Учебная деловая игра "Интеллектуальный хоккей" проводилась с целью развития интеллектуального потенциала студентов, обучающихся по профилю “Экскурсионная деятельность" в МГИФКСиТ им. Ю.А. Сенкевича. Данная деловая игра дает возможность студенту использовать навыки работы с информацией из различных источников на иностранном языке для решения профессиональных задач; позволяет демонстрировать профессиональную лексику и служит эффективным инструментом для закрепления знаний. Для эксперимента были выбраны студенты второго и третьего курса, обучающиеся по профилю "Экскурсионная деятельность". Предварительное анкетирование показало, что 50\% обучающихся испытывают трудности при усвоении страноведческой информации из-за обилия дат и объёма информации и необходимости вспомнить и воспроизвести нужную информацию в определенное время. Деловая игра позволяет студенту смоделировать реальную жизненную ситуацию и сформировать механизм принятия решений, а также расширить кругозор в области культурного наследия и развить смекалку и умение эффективно мыслить в условиях дефицита времени. 


\section{ПоряАок проведения игры}

1. Введение в игру. Этот этап знакомит участников с целью и основными задачами игры, правилами проведения и начисления баллов. Перед игрой участникам рассылается перечень тем, по которым будет проводиться игра. В данном случае цель игры - помочь участникам активизировать и обогатить знания в области культурного наследия, необходимые для студентов, изучающих экскурсионное дело. Темы вопросов включали в себя: историю Москвы, архитектуру Москвы, музеи столицы и объекты культурного наследия ЮНЕСКО. Перед игрой ведущим преподавателем было рекомендовано повторить эти аспекты с целью овладения дополнительной информацией, выходящей за рамки учебного плана.

2. Разделение на команды участников. В процессе подготовки игры выбирается капитан команды, в чью задачу входит выбор игроков. Общее количество игроков в каждой команде - 10 человек. Капитан вытягивает тему, по которой его команда готовит 10 вопросов для команды соперников без использования гаджетов. Задача преподавателя на данном этапе отследить релевантность вопросов и их грамматическую корректность. Командам дается 20 минут на подготовку вопросов.

3. Ход игры. Команды садятся напротив друг друга по следующей схеме: капитан команды, два нападающих и семь защитников. Проходит жеребьевка на право первого хода и капитан объявляет игровую категорию и задает вопрос. В течение первых 20 секунд право ответа предоставляется капитану команды, если он не смог ответить, то право передается нападающим, а затем защитникам. Участники команды не общаются между собой пока защитники или нападающие обсуждают вопрос. Если на вопрос дан правильный ответ - команда получает 5 баллов. Максимальное количество баллов за вопрос - 5, но при каждой передаче вопроса нападающим и защитникам теряется по баллу. Роль преподавателя на данном этапе игры - эксперт и судья для решения спорных вопросов и конфликтных ситуаций. Преподаватель должен мотивировать всех участников принимать активное участие и помогать в создании благоприятного психологического климата. Но, несмотря на то, что преподаватель должен управлять процессом ему не стоит вмешиваться в игру, следует разрешить участникам проявить разумную самостоятельность и отработать не только учебные навыки, но и навыки межличностного взаимодействия, что крайне необходимо для будущих работников туриндустрии.

4. Подведение итогов. На данном этапе преподаватель анализирует работу команд и оценивает принятые ими решения, сравнивает методику принятия решений и эффективность разных стратегий.
Особое внимание уделяется анализу культуроведческого материала и его профессиональная значимость. Преподаватель акцентирует внимание студентов, что посредством игры "Интеллектуальный хоккей" они закрепили и углубили полученные знания, которые им помогут в их профессиональной деятельности.

Первая часть эксперимента заключалась в выявлении отношения ППС и студентов к использованию игрового метода в обучении иностранному языку, для чего было проведено их анкетирование. Во второй части эксперимента были проанализированы результаты игры и их влияние на педагогический процесс.

На основании проведённых опросов преподавателей, были получены результаты, которые представлены в Таблице 1.

Таблица 1

Результаты анкетирования преподавателей

\begin{tabular}{|l|c|c|c|}
\multicolumn{1}{|c|}{ Вопрос анкеты } & "да" & "нет" & $\begin{array}{c}\text { "затрудняюсь } \\
\text { ответить" }\end{array}$ \\
\hline $\begin{array}{l}\text { Считаете ли Вы метод деловой игры со- } \\
\text { временной педагогической технологией? }\end{array}$ & $80 \%$ & $11 \%$ & $9 \%$ \\
\hline $\begin{array}{l}\text { Используете ли Вы игровые технологии в } \\
\text { работе по английскому языку? }\end{array}$ & $40 \%$ & $60 \%$ & - \\
\hline $\begin{array}{l}\text { Как Вы думаете, помогает ли игровая } \\
\text { технология в разноуровневом обучении? }\end{array}$ & $40 \%$ & $50 \%$ & $10 \%$ \\
\hline $\begin{array}{l}\text { С ддовольствием ли студенты участвуют } \\
\text { в игровой деятельности? }\end{array}$ & $68 \%$ & $27 \%$ & $5 \%$ \\
\hline
\end{tabular}

Большинство опрошенных педагогов считают игровой метод современной педагогической технологией, однако, предпочитают придерживаться привычной формы проведения занятий. Более того, преподаватели уверены, что проводить игры можно и нужно раз в семестр, не чаще. Такое отношение к использованию игровой методики объясняется тем, что создание деловой игры требует большой теоретической подготовки педагога. Кроме того, проведение игровой деятельности занимает много времени и, что немаловажно, преподавателю сложнее контролировать уровень знаний, полученных студентом во время участия в игре. Было отмечено, что в основном студенты с удовольствием участвуют в игровой деятельности и наилучшие результаты деятельности получаются именно при использовании игрового метода. Большинство преподавателей ждут улучшения результата своей работы, личного удовлетворения своим трудом, морального признания со стороны коллег.

На основании проведённых опросов студентов, были получены следующие результаты, которые представлены в Таблице 2. 
Таблица 2

Результаты анкетирования студентов

\begin{tabular}{|l|c|c|c|}
\hline \multicolumn{1}{|c|}{ Вопрос анкеты } & "да" & "нет" & $\begin{array}{c}\text { "затрудняюсь } \\
\text { ответить" }\end{array}$ \\
\hline $\begin{array}{l}\text { Принимали ли вы когда-либо участие в } \\
\text { игровой деятельности? }\end{array}$ & $63 \%$ & $37 \%$ & - \\
\hline $\begin{array}{l}\text { Помогает ли участие в игре не только } \\
\text { узнать новое и закрепить старое, но и } \\
\text { провести связь между другими пред- } \\
\text { метами? }\end{array}$ & $52 \%$ & $24 \%$ & $24 \%$ \\
\hline
\end{tabular}

Студенты уверены, что участие в игре помогает им не только узнать новое и закрепить старое, но и провести связь между другими предметами. Среди плюсов использования игрового метода были выделены необычность формы обучения, её новизна, возможность общаться с широким кругом людей, возможность самим добывать информацию и создавать что-то своё.

Данные проведённой диагностики показали, что преподаватели и студенты имеют как различия в отношении к использованию игрового метода на занятиях английского языка, так и общие точки зрения. Однако наряду с отличиями, учащиеся и преподаватели пришли к общему мнению, что участие в игре помогает не только узнать новое и закрепить старое, но и провести связь с другими предметами. Кроме того, студенты уверены, что использование игрового метода оказывает большое влияние на уровень их развития.

Согласно проведенному после деловой игры анкетированию, участники отметили ее значимость для усвоения профессиональной лексики для будущих гидов-экскурсоводов.

Также студенты указали, что подготовка к предлагаемой игре потребовала от них большой самостоятельной работы в интернете, что, как известно, "помогает студентам не только изучить язык, но и расширяет возможности студентов, учит их поиску необходимой информации, взаимодействию с другими студентами, развивает их навыки работы в команде" [5].

В процессе последующего мониторинга учебного процесса в группах, принявших участие в эксперименте, наблюдается положительная динамика роста не только уровня знаний по сравнению с группами, обучающимися по традиционным методикам, но и процента посещаемости занятий, что позволяет сделать вывод об успешно проведенном эксперименте и его значимости в процессе подготовки кадров для индустрии туризма. Также подтверждением эффективности эксперимента является улучшение межличностных контактов в группе, уме- ние разрешать конфликтные ситуации, толерантное отношение к чужому мнению. Для студентов, обучающихся по специальностям "Туризм" и "Гостиничный бизнес", понимание и принятие принципов толерантности является основополагающим в их дальнейшей профессиональной деятельности. Работа в гостиницах, туристических агентствах, компаниях туроператоров и в качестве гидов предполагает общение с клиентами и гостями различных национальностей и культур. Поэтому принципы толерантности, дружелюбного и терпимого отношения к этим представителям должны воспитываться еще в процессе обучения [3].

\section{Зак^ючение}

На основе результатов проведенного экспериментального обучения можно сделать следующие выводы:

Учебная деловая игра "Московский гид" является одним из важнейших методов формирования и развития профессионально-ориентированной коммуникативной компетенции и повышения мотивации студентов к изучению профессионально-ориентированного иностранного языка. Она повышает эффективность формирования таких важных умений и навыков для специалистов в сфере туризма и гостеприимства, как: языковые и коммуникативные навыки, навыки работы с информацией из различных источников и навыки работы со специализированной литературой. Подготовка студентов к игре и ее проведение значительно расширили словарный запас студентов и облегчили запоминание новой лексики.

Также эксперимент выявил повышение мотивации к изучению профессионально-ориентированного английского языка.

Студентам понравилась атмосфера дружеской конкуренции во время игры, что способствовало повышению их коммуникативной компетентности.

Полученные результаты подтвердили, что регулярное проведение деловых игр помогает сплотить коллектив, сформировать толерантное отношение студентов друг к другу.

В заключение можно сказать, что проведенное исследование доказало эффективность использования деловой игры "Интеллектуальный хоккей" для формирования профессионально-ориентированной коммуникативной компетенции. Авторы считают, что на основе данной деловой игры могут быть разработаны деловые игры на других языках и для других контингентов учащихся и рекомендуют включать ее в рабочие программы профессионального иностранного языка любой специальности. 


\section{ЛИТЕРАТУРА}

1. Артемьева 0.А. Общепедагогические и лингводидактические основы активизации познавательной деятельности студентов вузов при обучении иностранному языку на основе системы учебно-ролевых игр: автореф. дисс. ... д.п.н. [Электронный ресурс]. URL: https://www.dissercat.com/content/ obshchepedagogicheskie-i-lingvodidakticheskie-osnovy-aktivizatsii-poznavatelnoi-deyatelnosti (дата обращения: 05.10.2020).

2. Бершадский А.М., Янко Е.Е. Игровые компьютерные технологии в системе образования // Современная техника и технологии. 2016. № 9 [Электронный ресурс]. URL: http://technology.snauka.ru/2016/09/10429 (дата обращения: 01.10.2020).

3. Волкова А. Ю., Лапидус 0.А. Основные задачи и формы воспитания толерантности у студентов в процессе изучения иностранных языков при подготовке кадров для индустрии туризма и гостеприимства // Актуальные проблемы лингвистической подготовки в неязыковом вузе: сборник научных трудов II Международной научно-практической конференции. 18-20 февраля 2020 г. М.: МГИФКСиТ имени Ю.А. Сенкевича, 2020. С. 7-13

4. Глаголев А.Б. Роль и значение межкультурной компетенции при лингвистической подготовке студентов неязыкового вуза // Актуальные проблемы лингвистической подготовки в неязыковом вузе: сборник научных трудов II Международной научно-практической конференции. М.: МГИФКСиТ имени Ю.А. Сенкевича, 2020. С. 27-33.

5. Коршунова С.И. Использование Интернет в обучении профессионально-ориентированному иностранному языку в неязыковом вузе. // Актуальные проблемы лингвистической подготовки в неязыковом вузе: сборник научных трудов Международной научно-практической конференции. - 19 декабря 2018 г. М.: МГИИТ имени Ю.А. Сенкевича, 2018. С. 64-71.

6. Левченко 0.Ю. Обучение грамматике иностранного языка в неязыковом вузе. 2018. [Электронный ресурc]. URL :http://sibupk.su/upload/medialibrary/ cda/Левченк0\%200.Ю._ОБУЧЕНИЕ\%20ГРАММАТИКЕ\%20ИНОСТРАНННОГО\%20ЯЗЫКА.pdf (дата обращения: 05.10.2020).

7. Ляхова Е.Г. Психологические аспекты формирования профессиональной межкультурной иноязычной компетенции в неязыковом вузе // Вопросы филологии. М.: Институт иностранных языков, 2015.4 (52). С. $24-29$.

8. Ляхова Е.Г., Мороз Н.Ю., Цацкина Е.П. Инновационные методы формирования языковой профессиональной компетенции при обучении иностранному языку студентов-нелингвистов // Иностранный язык в свете профессиональной коммуникации: инновации, проблемы и перспективы. Сборник материалов Межвузовской научно-практической конференции. М.: Московский государственный лингвистический университет, 2019. С. 138-145.

9. Мишенева Ю.И. Игровые технологии как средства обучения профессиональному иноязычному общению студентов неязыковых вузов // Научно-методический электронный журнал «Концепт». - 2014. - № S21. - С. 41-45 [Электронный ресурс]. URL: http://e-koncept.ru/2014/14763.htm. (дата 0бращения: 05.10 .2020$)$.

10. Перфилова Г.В. Примерная программа по дисциплине «Иностранный язык» для подготовки бакалавров (неязыковые вузы). Москва: ИПК МГлУ «Рема», 2011.5 c.

11. Стародубцева Е.А Психосберегающие технологии обучения иностранному языку в языковом вузе: на материале преподавания английского языка: автореф. дисс. ... к.П.н. М.: МПГУ, 2007. 24 с.

12. Филиппова Н.Л. Актуальные проблемы формирования и развития иноязычной коммуникативной компетенции в неязыковом вузе. // Актуальные проблемы лингвистической подготовки в неязыковом вузе: сборник научных трудов II Международной научно-практической конференции. 18-20 февраля 2020 г. М.: МГИФКСиТ имени Ю.А. Сенкевича, 2020. С. 207-212

13. Фролова 0.А., Глаголев А.Б. Интенсификация процесса обучения профессионально-ориентированному иностранному языку с применением интерактивной технологии при подготовке кадров сферы гостеприимства и туризма// Индустрия туризма: возможности, приоритеты, проблемы и перспективы. 2018. T.13. № 5. C.415-422.

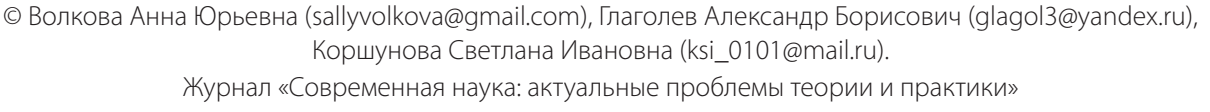

